[Jpn. J. Rural Econ. Vol. 4, pp. 1-10, 2002]

\title{
The Optimal Dynamic Model of Conjunctive Water Use
}

\author{
Chieko Umetsu*
}

This paper considers dynamic water allocation for the conjunctive use of surface water and groundwater. Conditions that determine temporal and spatial optimization problems are identified. Temporal allocation is governed by the Hotelling rule, which determines the optimal allocation of the initial stock of water for each period. On the other hand, the spatial allocation of water is constrained by the amount of the initial stock of surface water flow into the canal at each period. The optimal allocation of water results in allocating more water in the first period when fixed recharge to groundwater is available in later periods. As a result, the shadow price of water becomes less in later periods, providing incentives for farmers to use more water at the head of the canal. The results suggest that if the irrigation system deteriorates in later periods, the distribution of land rents in favor of head firms may be further intensified.

Key words: spatial water allocation, dynamic model, storage, conjunctive use.

\section{Introduction}

An early conjunctive use model (Burt [2]) studies optimal investment decisions over time among multiple storage facilities of water resources. Groundwater is considered not only a source of water stock, but also a storage for natural runoff, incidental recharge from the canal, and artificial recharge from surface storage. Other conjunctive use models incorporate dynamics (Young and Bredehoeft [14]; Gisser [7]); however, the spatial aspect of surface and groundwater allocation has not been given much attention until recently (Chakravorty et al. [5]). Furthermore, the literature that deals with the spatial dynamics of water allocation

\footnotetext{
* Research Program, East-West Center, Honolulu, U.S.A and Research Institute for Humanity and Nature, Kyoto, Japan.

This research was financially supported by the Grant-in-Aid for Scientific Research (C) of the Ministry of Education, Culture, Sports, Science and Technology, Japanese Government, Program No. 10660209, 1998-99. The author gratefully acknowledges Ujjayant Chakravorty, as well as the editor and two anonymous referees of JJRE for their valuable comments and insights that substantially improved the paper. I appreciate Regina Gregory for editorial assistance.
}

is scant.1. Kim et al. [9] elaborate on a dynamic model of groundwater use to consider endogenous cropping patterns with a pumping cost externality. However, a spatial dimension is again not given attention. We attempt to fill this gap by illustrating the economic principles that govern the efficient allocation of conjunctive water use over space and time.

This paper is concerned with the dynamic aspects of spatial conjunctive water use. The static spatial model discussed in Umetsu and Chakravorty $[11,12]$ is extended further to incorporate a dynamic dimension of water allocation. Section 2 defines the specification and the optimization problem for the optimal spatial dynamic model. Section 3 explains the method of simulation for this dynamic extension of the spatial model. Section 4 provides the simulation results. Section 5 concludes the paper with some policy implications.

\section{The Optimal Dynamic Model of Conjunctive Water Use}

The model considered here is a spatial dynamic optimal water allocation model for the conjunctive use of surface and groundwater. Section 2.1 illustrates the specification of the problem. The next part specifies the optimization problem of the dynamic spatial allocation of water. This is followed by the necessary 


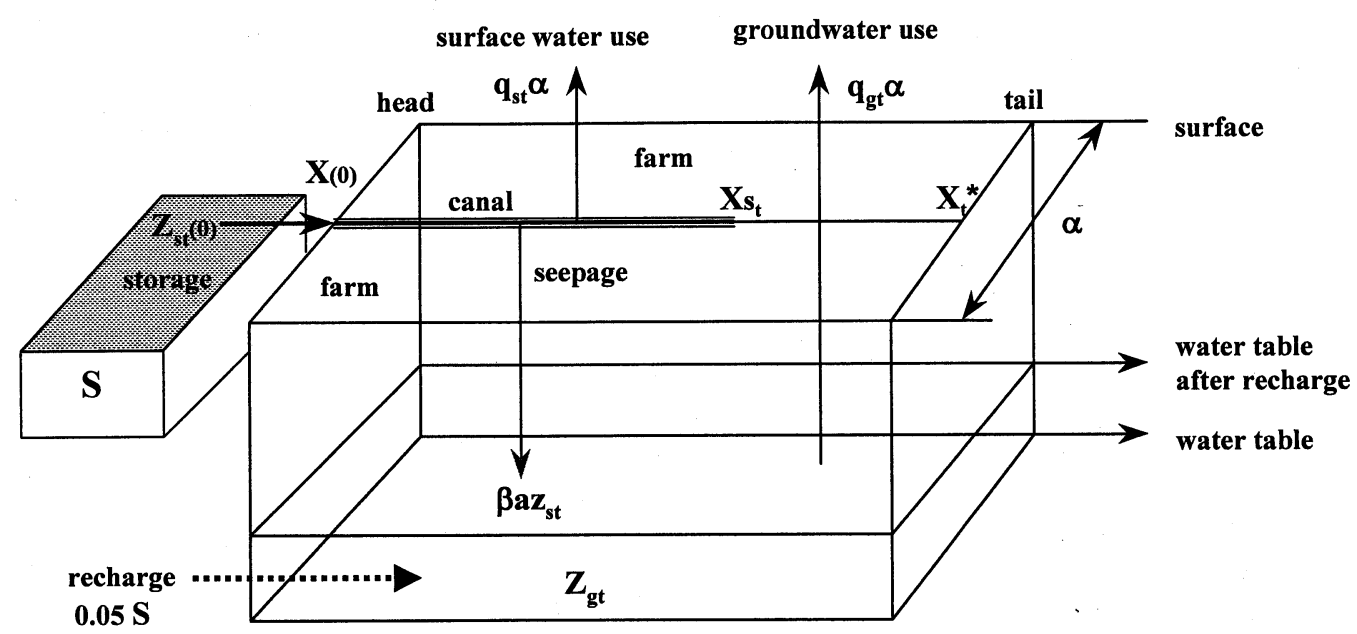

Figure 1. Water project area and an aquifer: the case of dynamic conjunctive water use

conditions for this optimization problem.

\section{1) Specification of the problem}

A utility is assumed to invest optimally over three time periods in a canal irrigation project, and it charges each agricultural firm the shadow price of water in the project area. Figure 1 shows the water project area and an aquifer in the case of dynamic conjunctive water use. The aquifer underlying the project area naturally recharges a fixed amount of water every year. Seepage from the canal also recharges the aquifer. The aquifer has a flat bottom, and seepage can move evenly across the aquifer without any time lag. Individual firms have a choice of using groundwater from the aquifer in conjunction with surface water, which is distributed through the irrigation canal. Also, a water storage facility is near the project area and the utility uses a certain amount of water each year from storage to generate water in the canal. The optimal allocation determines the optimal project area, the length of the canal, spatial surface and groundwater use, conveyance expenditure, and the optimal initial stocks of surface water for each time period. Monocropping, homogeneous land quality, and no uncertainty are assumed. Seepage from the field is not considered in this case.

The utility endogenously chooses the amount of the initial stock of surface water $z_{s t}(0)$ from a storage facility at the source $(x=0)$ of the canal for a period $t(t=1,2$, and $3)$. In this section, unless otherwise noted, subscripts $s, g$, and $t$ denote surface water, groundwater, and time period, respectively. The total surface water stock available in storage $S$ is fixed, and $S_{t}$ indicates water stock remaining in storage at period $t$ with $S>0$ and $S_{t} \geq 0$. Thus the total surface water constraint for three periods is given by:

$$
S=\sum_{t=1}^{3} z_{s t}(0) . z_{s t}(0) \geq 0 \quad(t=1,2,3)
$$

Let $g\left(z_{s t}(0)\right)$ be the cost of generating water and $g^{\prime}\left(z_{s t}(0)\right)$ the marginal cost of generating water at the source for each time period. ${ }^{2)}$ The quantity of surface water use per unit land area at location $x$ for time period $t$ is represented by $q_{s t}(x)$, groundwater use by $q_{g t}(x)$, and the fraction of water lost in conveyance per unit length of canal by $a_{t}(x)$. The residual quantity of water flowing in the canal per unit length at $x$ is $z_{s t}(x)$ for time period $t$. The change in the residual stock of water at each location for given period $t, z_{s t}{ }^{\prime}(x)$, is expressed by the total water used by firms, $q_{s t}(x) \alpha$, and the total water lost in the canal, $a_{t}(x) z_{s t}(x)$, as follows:

$$
z_{s t}^{\prime}(x)=-q_{s t}(x) \alpha-a_{t}(x) z_{s t}(x),(t=1,2,3)
$$

where $\alpha$ is the width of the project area. The water loss rate $a_{t}(x)$ is a function of conveyance expenditure $k_{t}(x)$ per unit surface area of the canal and is expressed by:

$a_{t}(x)=a_{0}-m\left(k_{t}(x)\right),(t=1,2,3)$ and

$$
a_{0} \in[0,1], m \in\left[0, a_{0}\right], a_{t}(x) \in[0,1]
$$
where $a_{0}$ is the constant base loss rate and $m\left(k_{t}(x)\right)$ is the reduction in conveyance loss 
rate with a given level of conveyance expenditure $k_{t}(x)$ for period $t$.

At each period, a fraction, $\beta=0.3$, of conveyance loss goes underground and recharges the aquifer. The change in the residual stock of groundwater at each location for a given period $t$ is expressed by the amount of recharge from canal to the aquifer, $\beta a_{t}(x) z_{s t}(x)$, and the amount of extraction of groundwater, $q_{g t}(x) \alpha$. Groundwater use is allowed only in period 2 and period 3. Thus state constraints are given by:

$$
\begin{gathered}
z_{g l}{ }^{\prime}(x)=\beta a_{1}(x) z_{s l}(x) \\
z_{g t}{ }^{\prime}(x)=\beta a_{t}(x) z_{s t}(x)-q_{g t}(x) \alpha .(t=2,3)
\end{gathered}
$$

Also, at the beginning of period 2 and period 3 , there is a fixed amount of natural recharge, $R$, flowing into the aquifer. For period 2, the initial stock of groundwater is the fixed recharge plus seepage accumulated in period 1 . Therefore the initial stock of groundwater for each period is different and given by:

$$
\begin{gathered}
z_{g 1}(0)=0, \\
z_{g 2}(0)=R+\int_{0}^{X^{*}} \beta a_{1}(x) z_{s 1}(x) d x, \\
z_{g 3}(0)=R,
\end{gathered}
$$

where $X^{*}{ }_{1}$ is the optimal length of the project area for period 1 .

Let us denote $\left(q_{s}(x)+q_{g}(x)\right)$ as applied water and $\left(q_{s}(x)+q_{g}(x)\right) h$ as effective water denoted by $e(x)$, i.e., water that is actually consumed for growth and evapotranspiration by the crop (Caswell and Zilberman [3]). Crop production is a function of effective water specified by $y=f[e(x)]$ where $y(x)$ is output per unit land area. The production function is assumed to be increasing, twice differentiable and decreasing in returns to scale with respect to a single input, effective water, so that $f(e)>0, \partial f / \partial e>0$, and $\partial^{2} f / \partial e^{2}<0$. The proportion of applied water delivered to the plant $h(I)$ is a function of on-farm investment, $I$. For simplicity, $h$ is assumed to be constant in this model $(h=0.9)$. Since this fraction is fixed, the level of on-farm investment, $I$, is also fixed. The assumption of fixed on-farm technology can be relaxed when we consider endogenous technology (Umetsu and Chakravorty [11]). This parameter represents the level of on-farm technology for water conservation. ${ }^{3)}$

\section{2) The optimization problem}

In summary, the water resource available for production in each period is as follows: In period 1, firms can use only surface water from the canal. There is no groundwater pumping in the first period. In period 2, they can use surface water in conjunction with groundwater (fixed recharge + seepage from canal in period 1 and period 2). In period 3 , surface water and groundwater (fixed recharge and seepage from canal in period 3) are available.

The utility is assumed to maximize total net benefit from the water project over time and space with respect to temporal and spatial decision variables. Temporal decision variables include the amount of initial stock of surface water allocated to each period:

$$
z_{s t}(0) \quad(t=1,2,3)
$$

Spatial decision (control) variables are the amount of surface water use, groundwater use, conveyance expenditure at each location $x$, and the optimal length of project area for each period, given the initial stock of water at the source of canal as follows:

$$
\begin{array}{cc}
q_{s t}(x) & (t=1,2,3) \\
q_{g t}(x) & (t=2,3) \\
k_{t}(x) & (t=1,2,3) \\
X_{t}^{*} \quad(t=1,2,3)
\end{array}
$$

The optimization problem is expressed as a maximization of the present value of total net benefit, $J_{t}$, from the spatial water allocation problem for three periods subject to the temporal resource constraint (1), the spatial state constraints (2), (4), (5), and the initial stock constraints (6), (7), and (8), as shown below.

$$
\begin{aligned}
& \underset{\substack{(g)(10)(11)(12)(13) \\
=}}{\operatorname{maximimize}} \sum_{t=1}^{3} J_{t}(1+r)^{1-t} \\
& \int_{0}^{X_{1}^{*}}\left\{\left[p f\left[\left(q_{s 1}\right) h\right]-I-F\right] \alpha-k_{1}\right\} d x-g\left(z_{s 1}(0)\right) \\
& \quad+\left\{\int _ { 0 } ^ { X _ { 2 } ^ { * } } \left\{\left[p f\left[\left(q_{s 2}+q_{g 2}\right) h\right]-I-F-w q_{g 2}\right]\right.\right. \\
& \left.\left.\left.\alpha-k_{2}\right] \alpha-k_{2}\right\} d x-g\left(z_{s 2}(0)\right)\right\}(1+r)^{-1} \\
& \quad+\left\{\int _ { 0 } ^ { X _ { s } ^ { * } } \left\{\left[p f\left[\left(q_{s 3}+q_{g 3}\right) h\right]-I-F-w q_{g 3}\right]\right.\right. \\
& \left.\left.\left.\alpha-k_{3}\right] \alpha-k_{3}\right\} d x-g\left(z_{s 3}(0)\right)\right\}(1+r)^{-2}
\end{aligned}
$$

where $p$ is the constant output price, assuming price-taking producers; $X_{t}^{*}$ is the optimal length of the project area for each period; $I$ is the expenditure of on-farm investment; and $F$ is the fixed cost of irrigated farming. A pumping cost, $w$, is assumed to be constant over the project area, $r$ is the discount rate per annum, 
and the unit cost of conveyance is considered to be unity. The temporal and spatial decision variables should satisfy necessary conditions of respective temporal and spatial optimization problems. The following two sections consider the necessary conditions of these problems.

3) Necessary conditions for temporal optimization

Temporal optimization is expressed as a discrete optimization problem. The temporal resource constraint (1) can be rewritten in a discrete form as follows:

$$
S_{t+1}=S_{t}-z_{s t}(0),(t=1,2,3)
$$

where $S_{t}$ is the water stock left in storage at period $t$. Equation (16) shows that the water stock in storage that will be left for the next period is the water stock for this period minus water used for canal irrigation in the same period so that $S_{1}=S$ and $S_{4}=0$. Thus the utility maximizes the objective function (14), or the present value of a stream of total net benefit for three periods, with respect to decision variables, $z_{s t}(0), \delta_{t}$, and $S_{t}(t=1,2,3)$, subject to a temporal resource constraint (16). The Lagrangian of this problem is given below:

$$
L=\sum_{t=1}^{3} J_{t}(1+r)^{1-t}+\sum_{t=1}^{3} \delta_{t}\left[-S_{t+1}+S_{t}-z_{s t}(0)\right],
$$

where $\delta_{t}$ is a Lagrangian multiplier at period $t$, that provides the temporal shadow price of the surface water resource. Let $z_{s t}{ }^{*}(0), \delta_{t}{ }^{*}$ denote the corresponding optimal values for this optimization problem. Assuming that the Lagrangian is concave in $z_{s t}(0)$ and the appropriate sufficiency condition is well met, the first-order necessary conditions for optimality are given as follows:

$\partial L / \partial z_{s t}(0):\left[\partial N B_{t} / \partial z_{s t}(0)-\partial g\left(z_{s t}(0)\right) / \partial z_{s t}(0)\right]$

$$
(1+r)^{1-t}=\delta t
$$

$\partial L / \partial \delta_{t}: S_{t+1}=S_{t}-z_{s t}(0)$,

$\partial L / \partial S_{t}: \delta_{t+1}=\delta_{t}$.

Equation (18) means that the marginal benefit of using one more unit of initial surface water is equal to the marginal cost of holding one more unit of water in storage. In other words, $\delta_{t}$ indicates the opportunity cost of a resource that is the discounted stream of returns the utility would receive by using one additional unit of the surface water resource from storage. Equation (19) is simply a restatement of the resource constraint (16). Equation (20) shows that the increased return from holding one more unit of surface water in storage today is equivalent to the increased return from holding one more unit in the next period.

The marginal cost of generating water, $g^{\prime}\left(z_{s t}(0)\right)$, is equal to the spatial shadow price of surface water at the source from the salvage value condition. Using this relationship and equations (18) and (20), we can derive a relationship similar to the Hotelling rule of exhaustible resource extraction (Hotelling [8]) as follows:

$\left\{\left(M N B_{t+1}-\lambda_{s, t+1} *(0)\right)-\left(M N B_{t}-\lambda_{s t} *(0)\right)\right\} /$ $\left(M N B_{t}-\lambda_{s t}{ }^{*}(0)\right)=r$,

where $M N B_{t}=\partial N B_{t} / \partial z_{s t}(0), \lambda_{s t}{ }^{*}(0)=g^{\prime}\left(z_{s t}(0)\right)$, and $r$ is the discount rate. The marginal net benefit of the water project minus the marginal cost of generating water, i.e., the shadow price of surface water at the source for period $t,\left(M N B_{t}-\lambda_{s t}{ }^{*}(0)\right)$, indicates rents of water resources generated from the project by using the resource in the form of surface and groundwater. This condition states that the rate of change of rents generated from using surface water is equivalent to the discount rate. This condition relates the initial spatial shadow price of the resource for each period with dynamic optimality conditions.

\section{4) Necessary conditions for spatial optimi- zation}

Once the initial stock of surface water at each period is defined according to the necessary conditions of the dynamic optimization problem, it will be followed by the spatial optimization problem with a given surface water stock. Therefore spatial allocation is constrained by the allocation of surface water for each period. Let $\lambda_{s t}$ and $\lambda_{g t}$ be co-state variables for the surface and groundwater resource stocks at period $t$, respectively. The Hamiltonian for this spatial optimization problem for each period is defined as:

$H\left(q_{s t}, q_{g t}, k, \lambda_{s t}, \lambda_{g t}\right)=\left[p f\left[\left(q_{s t}+q_{g t}\right) h\right]-I-F\right.$
$\left.-w q_{g t}\right] \alpha-k_{t}-\lambda_{s t}\left[q_{s t} \alpha+a_{t} z_{s t}\right]+\lambda_{g t}\left[\beta a_{t} z_{s t}-q_{g t} \alpha\right]$.
$\quad\left(t=1,2,3 ; q_{g 1}=0\right)$. Assume that the Hamiltonian is concave in $q_{s t}(x), q_{g t}(x), k_{t}(x), z_{s t}(x)$, and, $z_{g t}(x)$ and the second-order sufficiency condition is well satisfied. Also assuming the possibility of a corner solution, the first-order necessary conditions for spatial optimality with the transversality condition for period 1 are given by:

$$
p f^{\prime} h \leq \lambda_{s l}
$$




$$
\begin{gathered}
\lambda_{s 1}{ }^{\prime}=a_{1}\left(\lambda_{s 1}-\beta \lambda_{g 1}\right), \\
\lambda_{g 1}{ }^{\prime}=0, \\
\left(\lambda_{s 1}-\beta \lambda_{g 1}\right) z_{s 1} m^{\prime}\left(k_{1}\right) \leq 1, \\
{\left[H\left(q_{s 1}, q_{g 1}, k_{1}, \lambda_{s 1}, \lambda_{g 1}\right)\right]_{x=X_{1}^{*}}=0,}
\end{gathered}
$$

and similarly for period 2 and $3(t=2,3)$ with groundwater production:

$$
\begin{gathered}
p f^{\prime} h \leq \lambda_{s t}, \\
p f^{\prime} h \leq w+\lambda_{g t}, \\
\lambda_{s t}{ }^{\prime}=a_{t}\left(\lambda_{s t}-\beta \lambda_{g t}\right), \\
\lambda_{g t}{ }^{\prime}=0, \\
\left(\lambda_{s t}-\beta \lambda_{g t}\right) z_{s t} m^{\prime}\left(k_{t}\right) \leq 1, \\
{\left[H\left(q_{s t}, q_{g t}, k_{t}, \lambda_{s t}, \lambda_{g t}\right)\right]_{x=X_{t}^{*}}=0,}
\end{gathered}
$$

where $f^{\prime}=\partial f / \partial q_{s t}, m^{\prime}=\partial m / \partial k_{t}$, and $\lambda_{s t}{ }^{\prime}=d \lambda_{s t} /$ $d x$. The conditions (23) and (28) state that the marginal value product, which is the marginal benefit, of surface water is equal to or less than the shadow price of surface water, which is the marginal cost of surface water production. The condition (29) similarly states that in case of groundwater production, the marginal value product of groundwater is equal to or less than the pumping cost plus the shadow price of groundwater, which is the marginal cost of groundwater. Conditions (24) and (30) indicate that the change in shadow price of surface water is determined by the water loss rate in the canal, $a_{t}(x)$, and the net shadow price of surface water in the canal as a result of seepage, $\left(\lambda_{s t}-\beta \lambda_{g t}\right)$. Thus from this condition, the change in shadow price of surface water is increased by a higher loss rate and higher shadow price of surface water, and it is decreased by a higher shadow price of groundwater. The conditions (25) and (31) state that the shadow price of groundwater does not change over space. The conditions (26) and (32) state that the marginal benefit of increasing one unit of conveyance expenditure is equal to or less than the marginal cost of conveyance expenditure, which is unity. The marginal benefit of conveyance expenditure is the increase in residual flow at location $x$ by increasing one more unit of conveyance, $z_{s t} m^{\prime}\left(k_{t}\right)$, times the net shadow price of surface water in the canal, $\left(\lambda_{s t}-\beta \lambda_{g t}\right)$. Finally, equations (27) and (33) show the transversality conditions for a free terminal point problem (Chiang [6]). They state that at the tail of the project area, the net benefits from the project are exactly offset by the shadow value of water at the tail.

\section{Data and Method of Simulation}

The revenue function ${ }^{4}$ for California cotton production is defined as a quadratic function of effective water ${ }^{5}$ in $\mathrm{m}^{3}$ with the output price of cotton being US $\$ 0.75$ per $1 \mathrm{~b}$.

$$
P f(e)=-0.2224+1.0944 e-0.5894 e^{2} \text {. }
$$

The water efficiency function is a function of on-farm investment (US $\$ / \mathrm{m}$ ) and defined as follows:

$$
h(I(x))=0.6+21.67 I-333.3 I^{2} .
$$

The water loss function is a function of conveyance expenditure (US $\$ / \mathrm{m}$ ) and thus is given by:

$$
a(k(x))=4 \times 10^{-5}-\left(4 \times 10^{-7} k-10^{-9} k^{2}\right),
$$

where the base loss rate is $a_{0}=4 \times 10^{-5}$ and the loss reduction function is $m(k)=4 \times 10^{-7} k-$ $10^{-9} k^{2}$.

The long-run marginal cost function for water generation is a function of the initial stock of water, $z_{s t}(0)$, in $\mathrm{m}^{3}$ and is defined as follows:

$g^{\prime}\left(z_{s t}(0)\right)=0.003785+\left(3.785 \times 10^{-11}\left(z_{s t}(0)\right)\right)$.

In this model, the level of on-farm investment, $I$, is fixed at US $\$ 0.020 / \mathrm{m}^{2}$ so that the water efficiency, i.e., the proportion of water delivered to the plant, $h$, is fixed at 0.9 . The total stock constraint, i.e., the total amount of water in storage, $S$, is fixed as $90 \times 10^{8} \mathrm{~m}^{3}$ ( 9 billion cubic meters). The recharge at the beginning of period 2 and 3 is equal to $0.05^{*} S$ which amounts to $4.5 \times 10^{8} \mathrm{~m}^{3}$. The values for other parameters are: width of the project area $10^{5} \mathrm{~m}$, seepage rate 0.3 , fixed cost of on-farm investment, $F$, US $\$ 0.107 / \mathrm{m}^{2}$, and pumping cost US $\$ 0.0128 / \mathrm{m}^{3}$. The discount rate is assumed to be $10 \%$ per annum.

Figure 2 depicts a schematic framework of the algorithm for a 3-period dynamic conjunctive water use model. The fixed surface water stock, $S$, is allocated over three periods using two distribution parameters, $\Delta$ and $\Gamma$, that change from 0 to 1 (or 1 to 0 ). Initially, a portion of water from storage, $\Delta S$, is distributed to period 1 as the initial stock of water into the canal. Then the remaining water stock in storage, $(1-\Delta) S$, is allocated the use or another distribution parameter $\Gamma$ so that $\Gamma(1-\Delta) S$ is allocated to period 2 , and $(1-\Gamma)(1-\Delta) S$ is allocated to period 3. Once the distribution of water for three periods is determined, a spatial 


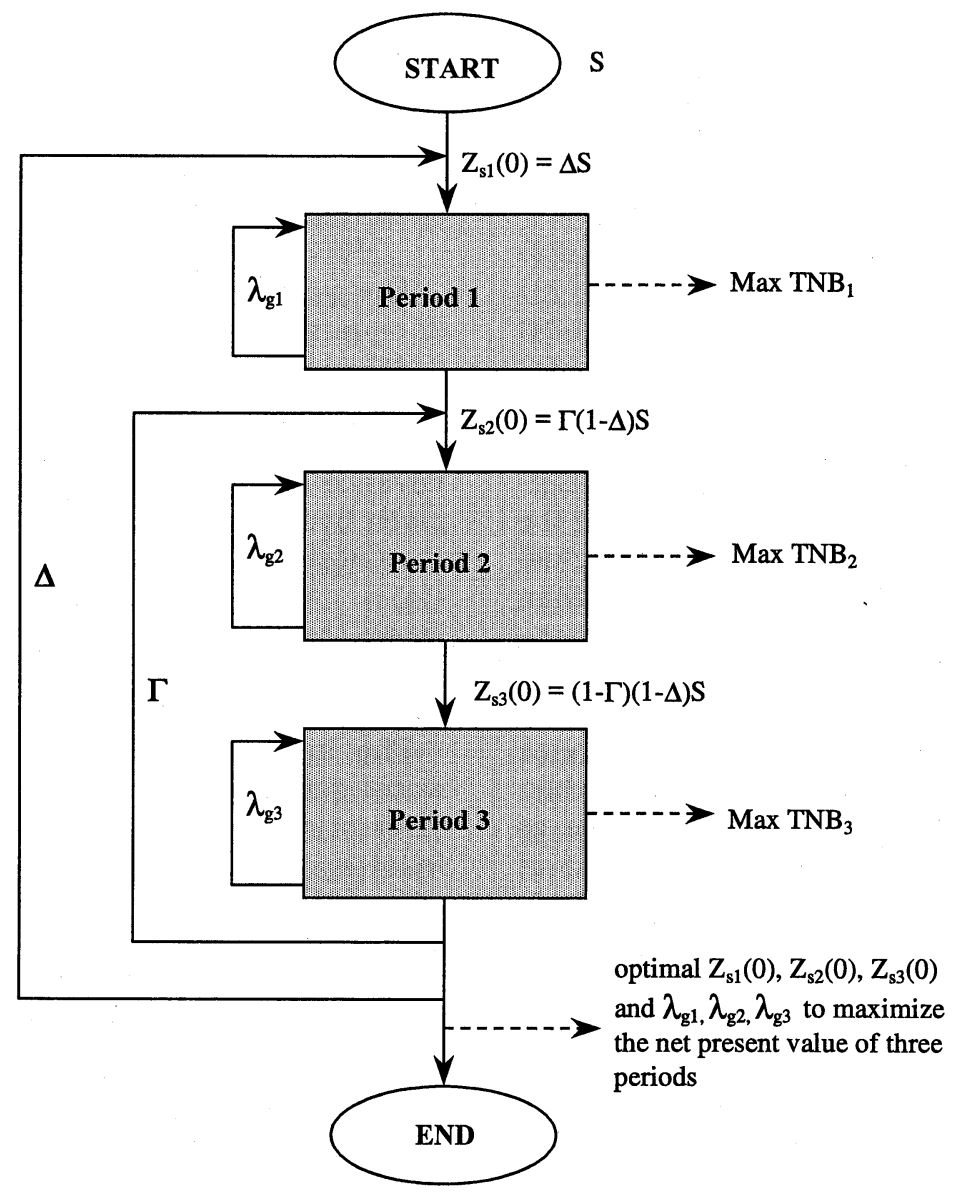

Figure 2. Algorithm for 3-period dynamic conjunctive water use model

allocation follows given the initial stock of water, by simulating the optimal shadow price of groundwater that maximizes the total net benefit for each period. Except for the fixed on-farm investment, the algorithm for the spatial allocation is almost the same as the one shown in Umetsu and Chakravorty [11].

When the spatial allocation of water for each period defines the maximum total net benefit, present value of the three periods is estimated at the end. This is the end of one cycle. After one cycle is completed, a different $\Gamma$ is assumed to distribute water to periods 2 and 3 . When $\Gamma$ reaches the maximum (or minimum) value, a different $\Delta$ is assumed and this cycle is repeated. The maximum present value defines the optimal combination of $\Delta$ and $\Gamma$, which in turn defines the optimal dynamic allocation of surface water for three periods.
Also, the maximum present value determines the optimal shadow price of groundwater for each period.

\section{Results of Simulation}

Table 1 shows the results of simulation for a 3-period dynamic conjunctive water use model. As mentioned in sections 2.3 and 2.4, temporal optimization is governed by the Hotelling rule, and the spatial optimization is controlled by the maximum principle. Furthermore, the allocation of the initial stock of water is constrained by the maximum allowable stock of water the canal can hold to produce non-negative land rents. When the initial stock of water becomes greater than $41 \times 10^{8}$ $\mathrm{m}^{3}$, the initial shadow price becomes too high and no production occurs because of negative land rents. 
Table 1. Three-period dynamic conjunctive water use model: seepage in the canal and fixed recharge with fixed on-farm technology

(discount rate $=0.10)$

\begin{tabular}{|c|c|c|c|c|c|}
\hline \multirow[b]{2}{*}{ Parameter } & \multirow[b]{2}{*}{ Unit } & \multirow[b]{2}{*}{ Total } & \multicolumn{3}{|c|}{ Period } \\
\hline & & & $\begin{array}{c}1 \\
\text { (surface) }\end{array}$ & $\begin{array}{c}2 \\
\text { (surface+ } \\
\text { ground) }\end{array}$ & $\begin{array}{c}3 \\
\text { (surface+ } \\
\text { ground) }\end{array}$ \\
\hline Total net benefit & $\left(10^{8} \mathrm{US} \$\right)$ & & 3.25 & 3.71 & 3.71 \\
\hline Total net benefit (NPV) & $\left(10^{8}\right.$ US $\left.\$\right)$ & 9.68 & 3.25 & 3.37 & 3.06 \\
\hline Area irrigated & $\left(10^{3} \mathrm{ha}\right)$ & 1120 & 400 & 360 & 360 \\
\hline$X_{S}$ & $(\mathrm{~km})$ & & 40 & 30 & 30 \\
\hline$X^{*}$ & $(\mathrm{~km})$ & & n.a. & 36 & 36 \\
\hline Initial surface water stock & $\left(10^{8} \mathrm{~m}^{3}\right)$ & 90 & 35 & 27.5 & 27.5 \\
\hline Allocation of initial water stock & & 1.000 & .390 & .305 & .305 \\
\hline Cost of generating water & $\left(10^{8}\right.$ US \$ ) & & 2.45 & 1.53 & 1.53 \\
\hline Initial groundwater stock & $\left(10^{8} \mathrm{~m}^{3}\right)$ & & 0 & 4.503 & 4.500 \\
\hline Aggr. output & $\left(10^{8} \mathrm{US} \$\right)$ & & 11.00 & 10.06 & 10.06 \\
\hline Aggr. net benefit & $\left(10^{8} \mathrm{US} \$\right)$ & & 5.72 & 5.23 & 5.24 \\
\hline Aggr. land rent & $\left(10^{8}\right.$ US $\left.\$\right)$ & & .89 & 1.73 & 1.74 \\
\hline Aggr. water rent & $\left(10^{8}\right.$ US \$ ) & & 4.82 & 3.49 & 3.50 \\
\hline$k(0)$ & (US $\$ / \mathrm{m})$ & & 198.45 & 197.67 & 197.66 \\
\hline$k\left(X_{s}\right)$ & (US $\$ / \mathrm{m})$ & & 143.64 & 146.61 & 146.48 \\
\hline$a(0)$ & $\left(10^{-3} / \mathrm{km}\right)$ & & .00240 & .00543 & .00546 \\
\hline$a\left(X_{s}\right)$ & $\left(10^{-3} / \mathrm{km}\right)$ & & 3.1767 & 2.8507 & 2.8641 \\
\hline$q_{s}(0)$ & $\left(\mathrm{m}^{3} / \mathrm{m}^{2}\right)$ & & $\begin{array}{l}.8750 \\
.8745^{*}\end{array}$ & .9049 & .9049 \\
\hline$q_{g}$ & $\left(\mathrm{~m}^{3} / \mathrm{m}^{2}\right)$ & & n.a. & .9012 & .9006 \\
\hline$I_{s}(0)$ & $\left(\mathrm{US} \$ / \mathrm{m}^{2}\right)$ & & .0200 & .0200 & .0200 \\
\hline & $\left(\mathrm{USS} \$ / \mathrm{m}^{2}\right)$ & & n.a. & .0200 & .0200 \\
\hline$h_{s}(0)$ & & & .9000 & .9000 & .9000 \\
\hline$h_{g}$ & & & n.a. & .9000 & .9000 \\
\hline$y_{s}(0)$ & $\left(\mathrm{US} \$ / \mathrm{m}^{2}\right)$ & & .26834 & .27199 & .27199 \\
\hline$y_{g}$ & $\left(\mathrm{US} \$ / \mathrm{m}^{2}\right)$ & & .26827 & .27159 & .27152 \\
\hline Net benefit (head) & $\left(\mathrm{USS} \$ / \mathrm{m}^{2}\right)$ & & .1394 & .1430 & .1430 \\
\hline Net benefit (tail) & $\left(\mathrm{US} \$ / \mathrm{m}^{2}\right)$ & & .1413 & .1331 & .1330 \\
\hline$\lambda_{s}(0)$ & $\left(\mathrm{USS} \$ / \mathrm{m}^{3}\right)$ & & $\begin{array}{l}.13664 \\
.13714^{*}\end{array}$ & .10768 & .10768 \\
\hline$w+\lambda_{g}$ & $\left(\mathrm{US} \$ / \mathrm{m}^{3}\right)$ & & .16194 & .11128 & .11188 \\
\hline$\lambda_{g}$ & $\left(\mathrm{USS} \$ / \mathrm{m}^{3}\right)$ & & .14914 & .09848 & .09908 \\
\hline$R_{L}(0)$ & $\left(10^{6} \mathrm{US} \$ / \mathrm{m}^{2}\right)$ & & 2.1780 & 4.7551 & 4.7551 \\
\hline$R_{L g}$ & $\left(10^{6} \mathrm{US} \$ / \mathrm{m}^{2}\right)$ & & 2.1343 & 4.4303 & 4.3762 \\
\hline$R_{W}(0)$ & $\left(10^{6} \mathrm{US} \$ / \mathrm{m}^{2}\right)$ & & 11.7580 & 9.5467 & 9.5467 \\
\hline$R_{W g}$ & $\left(10^{6} \mathrm{US} \$ / \mathrm{m}^{2}\right)$ & & 11.9931 & 8.8750 & 8.9230 \\
\hline
\end{tabular}

Note: n.a. = not applicable; $R_{L}=$ land rents; $R_{W}=$ water rents; $X_{s}$ and $X^{*}$ are distances from the head of the canal; loss rate is for a $1 \mathrm{~km}$ length of the canal; annual recharge of $4.5\left(10^{8} \mathrm{~m}^{3}\right)$ to the aquifer is added to the initial stock of surface water for periods 2 and 3 ; $*$ indicates figures at the tail. 
The present value of total net benefit for three periods is US $\$ 9.68 \times 10^{8}$, and the current value of total net benefit is US $\$ 3.25 \times 10^{8}$ for period 1 and a higher value, US $\$ 3.71 \times 10^{8}$, for periods 2 and 3 . However, the area irrigated, the length of canal, and the initial stock of water are highest for period 1, and have the same lower values for periods 2 and 3 . Of the total stock of surface water in storage, $90 \times 10^{8}$ $\mathrm{m}^{3}, 39 \%$ is allocated to period 1 and $30.5 \%$ each to periods 2 and 3 . These allocations result in a higher initial shadow price of surface water at the source in period 1 compared to periods 2 and 3. The temporal allocation of the surface water resource is not sensitive to a change in the discount rate. If a higher discount rate, 0.20 , or a lower discount rate, 0.05 , is assumed, this will not alter the allocation of the initial stock of surface water for each period. Moreover, a change in the fixed recharge does not change the allocation because fixed recharge does not affect the marginal conditions. ${ }^{6}$

A higher total net benefit accrues to periods 2 and 3 compared to period 1 despite a smaller stock of water resource including the allocation of surface water and the recharge to the groundwater for periods 2 and 3 . This is because a smaller surface water allocation saves the cost of generating water at the source. Also, due to the decrease in surface water, the length of the canal shrinks from $40 \mathrm{~km}$ in period 1 to $30 \mathrm{~km}$ in periods 2 and 3 . Furthermore, the significant amount of recharge in periods 2 and 3 to the aquifer extends the groundwater production for $6 \mathrm{~km}$ at the tail, covering 11\% of the total project area.

The allocation of a $21 \%$ higher initial stock of water in period 1 also leads to an $8.5 \%$ higher aggregate output and a $9.4 \%$ higher net benefit. Moreover, the higher allocation of surface water in period 1 provides a higher shadow price of surface water. As a result, aggregate land rents are $48.6 \%$ lower and aggregate water rents $38.1 \%$ higher in period $1 \mathrm{com}$ pared to periods 2 and 3 . As water becomes cheaper, the difference between the head and tail firms of land rents and water rents becomes larger. The difference of land rents between head and tail firms increases from $2 \%$ in period 1 to $7.3 \%$ in periods 2 and 3 .

The conveyance expenditures in periods 2 and 3 are $0.4 \%$ lower than in period 1 because of a lower initial stock of water and a shadow price of surface water. In period 2 , the conveyance expenditure is slightly higher than in period 3 because a higher initial stock of groundwater makes the optimal shadow price of groundwater less compared to period 3 . Also, higher shadow prices of surface water and groundwater in period 1 induces lower water use for firms and output and thus lowers net benefit per unit of land in period 1. On the other hand, lower shadow prices in period 2 and period 3 generate a $2.6 \%$ higher net benefit accompanied by $3.4 \%$ higher water use at the head.

The results of simulation for a 3-period dynamic conjunctive water use model are summarized as follows:

1) The allocation of the initial stock of water, $40 \%$, is highest for period 1 , and the same amount of $30 \%$ for periods 2 and 3 ; these allocations are not sensitive to a change in the discount rate. Fixed recharge does not affect the marginal conditions of water allocation.

2) The temporal allocation of water determines the initial level of the shadow price of surface water at the source of the canal and the spatial allocation of water for each period.

3) Despite a smaller allocation of the initial stock of water for periods 2 and 3 and the resulting lower shadow prices of surface water and groundwater, the total net benefit is $14 \%$ higher as a result of groundwater recharge and the cost saving of generating surface water. On the other hand, the area irrigated is $10 \%$ less and the length of the canal is $25 \%$ less than for period 1. Groundwater is used for $11 \%$ of total project area in periods 2 and 3.

4) A low shadow price of water provides $0.4 \%$ lower conveyance expenditure and $3.4 \%$ higher water use at the head in periods 2 and 3.

5) Aggregate land rents in periods 2 and 3 are twice the rents in period 1 . Moreover, the difference in land rents between head and tail firms increases to $7.3 \%$ in periods 2 and 3 , from $2 \%$ in period 1 , because of cheap water.

\section{Conclusion}

This paper expands the static spatial allocation of the conjunctive use model to consider a dynamic dimension. Conditions that determine temporal and spatial optimization problems are identified. Temporal allocation is governed by the Hotelling rule that determines the 
optimal allocation of the initial stock of water for each period. On the other hand, the spatial allocation of water is constrained by the amount of the initial stock of surface water flow into the canal at each period. In this model, the recharge to groundwater is fixed; therefore the amount of groundwater does not significantly affect the temporal allocation of surface water. Moreover, the model is not sensitive to a change in the discount rate because of a short time horizon.

The above results provide some significant policy implications. The optimal allocation of water results in allocating more water in the first period when a fixed recharge to groundwater is available for periods 2 and 3 . As a result, the shadow price of water becomes less in later periods providing incentives for farmers to use more water at the head of the canal. The utility must be aware that a smaller allocation of water creates a distributional inequity of land rents among firms because of a low shadow price of water. If the irrigation system deteriorates in later periods, the distribution of land rents in favor of head firms may be further intensified. If the utility wishes to achieve distributional equity, policy measures to compensate tail firms - for example, to use a portion of benefits from the efficient temporal allocation for compensation - would be warranted.

In this model, the conveyance cost is the same for three periods. The model can be extended by using higher loss functions so that the conveyance expenditure becomes more expensive in later periods. This reflects the deterioration of the canal system over time and may be accompanied by adverse environmental problems such as waterlogging, salinization, or contamination of groundwater by fertilizers and pesticides, since water is a major transport mechanism of pollutants (Boggess et al. [1]). And if the water generating cost at the source is a function of the cumulative water resources used in the past, the allocation of water will be shifted to earlier periods to take advantage of cheaper water generation cost. Although a short time horizon does not indicate changes in allocation over time because of a change in the discount rate, if the horizon is expanded to 10 or 20 years, the model may become sensitive to a change in the discount rate. If the shape of the aquifer is complicated so that water flow is restricted within it as a result of the slope or clay soil at the bottom, the groundwater availability is not equal among firms, and different specification of the model may be required.

1) For example, Takayama and Judge [10] discuss models for intertemporal and spatial price equilibrium problems with multiple commodities and multiple regions. However, the work regarding water resource allocation problems is very scarce.

2) Another interesting specification of the cost of generating water must be the case when the cost is a function of cumulative water stock extracted from the storage. In this specification, similar to a mining problem, the cost of generating water increases drastically, and if one uses more surface water in storage for the canal today, it becomes more costly to extract the remaining water in the next period.

3) In reality, the irrigation effectiveness varies from 0.6 under traditional furrow irrigation to 0.85 and 0.95 under modern sprinkler and drip irrigation (Caswell and Zilberman [4]).

4) For a detailed explanation of the functional forms, please see Umetsu and Chakravorty [11].

5) Caswell and Zilberman [4] compared CobbDouglas and quadratic production functions and concluded that in California, where modern irrigation technologies such as drip and sprinkler are widely used, a quadratic production function, which has flexible output elasticity, has shown more reasonable outcomes. Also Yaron and Bresler [13] compared water response functions with quadratic and cubic forms.

6) If recharge is a variable, for example a function of allocated initial stock of surface water for each period, the amount of recharge will affect the marginal conditions and thus the allocation of the initial stock of water for each period.

\section{References}

[1] Boggess, W., R. Lacewell, and D. Zilberman. "Economics of Water Use in Agriculture," in Carson, G. A., D. Zilberman, and J. A. Miranowski, eds., Agricultural and Environmental Resource Economics. New York: Oxford University Press, 1993.

[2] Burt, O. R. "The Economics of Conjunctive Use of Ground and Surface Water," Hilgardia, Vol. 36, 1964, pp. 31-111.

[3] Caswell, M. and D. Zilberman. "The Choices of Irrigation Technologies in California," American Journal of Agricultural Economics, Vol. 67, 1985, pp. 224-234.

[4] Caswell, M. and D. Zilberman. "The Effects of Well Depth and Land Quality on the Choice of Irrigation Technology," American Journal of 
Agricultural Economics, Vol. 68, 1986, pp. 798-811.

[5] Chakravorty, U., E. Hochman, and D. Zilberman. "A Spatial Model of Optimal Water Conveyance," Journal of Environmental Economics and Management, Vol. 29, 1995, pp. 25-41.

[6] Chiang, A. C. Elements of Dynamic Optimization. New York: McGraw-Hill, 1992.

[7] Gisser, M. "Groundwater: Focusing on the Real Issue," Journal of Political Economy, Vol. 91, 1983, pp. 1001-1027.

[8] Hotelling, H. "The Economics of Exhaustible Resources," Journal of Political Economy, Vol. 39, 1931, pp. 137-175.

[9] Kim, C. S., M. R. Moore, and J. J. Hanchar. "A Dynamic Model of Adaptation to Resource Depletion: Theory and an Application to Groundwater Mining," Journal of Environmental Economics and Management, Vol. 17, 1989, pp. 66-82.

[10] Takayama, T. and G. G. Judge. Spatial and Temporal Price and Allocation Models. Amsterdam:
North-Holland Pub. Co., 1971.

[11] Umetsu, C. and U. Chakravorty. "Water Conveyance, Return Flows and Technology Choice," Agricultural Economics, Vol. 19, 1998, pp. 181-191.

[12] Umetsu, C. and U. Chakravorty. "Water Conveyance Costs and Conjunctive Use," International Journal of Social Economics, Vol. 27, 2000, pp. 1020 $-1036$.

[13] Yaron, D. and E. Bresler. "Economic Analysis of On-farm Irrigation Using Response Functions of Crops," In H. Hillel, ed., Advances in Irrigation. Vol. 2. New York: Academic Press, 1983.

[14] Young, R. A. and J. D. Bredehoeft. "Digital Computer Simulation for Solving Management Problems of Conjunctive Groundwater and Surface Water Systems," Water Resources Research, Vol. 8, 1972, pp. 533-556.

(Received February 7, 2001; accepted June 4, 2001) 